\title{
LOS INMIGRANTES SIRIO-LIBANESES Y SU INSERCIÓN TERRITORIAL EN EL SUDESTE DE RÍO NEGRO, ARGENTINA (1912-1930)
}

MATÍAS RODRIGO CHÁVEZa

\section{RESUMEN}

Este trabajo analiza la inserción territorial de los inmigrantes árabes en el sudeste del Territorio Nacional de Río Negro durante las primeras décadas del siglo XX, utilizando como fuente principal las inspecciones realizadas por la Dirección General de Tierras. Se busca reconstruir las tensiones y los conflictos entre los inspectores de tierras y los ocupantes sirio-libaneses, demostrando que estos últimos escaparon a los sistemas de clasificación binarios que dividían a los pobladores en europeos e indígenas. Se argumenta que los inmigrantes árabes desplegaron estrategias territoriales condicionadas por sus intereses comerciales, generando ocupaciones caracterizadas por su alta movilidad e inestabilidad y cuyo principal objetivo era consolidar nodos mercantiles a partir de los cuales tender redes de negocios.

PALABRAS CLAVE: Patagonia, inmigración, sirio-libaneses, tierra pública.

\section{THE SYRIAN-LEBANESE IMMIGRANTS AND THEIR TERRITORIAL INSERTION IN THE SOUTHEAST OF RÍO NEGRO, ARGENTINA (1912-1930)}

\begin{abstract}
This paper analyzes the territorial insertion of Arab immigrants in the southeast of the National Territory of Río Negro during the first decades of the 20th century. The main source are the inspections carried out by the General Land Direction. We seek to reconstruct the tensions and conflicts between the land inspectors and the Syrian-Lebanese occupants, showing that the latter escaped the binary clasiffication systems that divided the settlers into European and indigenous. We argue that Arab immigrants displayed territorial strategies conditioned by their commercial interests, generating occupations characterized by their high mobility and instability and whose main objective was to consolidate mercantile nodes from which they could build up business networks.
\end{abstract}

KEY WORDS: Patagonia, immigration, Syrian-Lebanese, public land. 
Pobladores árabes, tierra pública y estado en el sudeste de Río Negro1

Este artículo propone historiar la inserción territorial y las estrategias de acceso a la tierra de los inmigrantes sirio-libaneses en el sudeste del Territorio Nacional de Río Negro durante las primeras décadas del siglo $\mathrm{XX}^{2}$. Para ello se reconstruyen las tensiones que se produjeron entre los pobladores árabes y los inspectores de tierras, considerando que estos funcionarios demostraron preferencias por los inmigrantes europeos y atribuyeron supuestas limitaciones a los inmigrantes sirio-libaneses.

La principal fuente utilizada son los documentos que produjeron las inspecciones de la Dirección General de Tierras entre 1904 y 1930 , materiales que se encuentran disponibles en el Archivo Histórico de la Provincia de Río Negro (AHPRN). El recorte temporal se inicia en 1912, año en el que los funcionarios de tierras registraron a los primeros pobladores árabes en la región, y se cierra en 1930 cuando comenzó a declinar el ciclo migratorio de los sirio-libaneses. El trabajo se centra en Valcheta y sus zonas de influencia, considerando que la dinámica de esa región puede ser representativa de la inserción de los pobladores árabes en el resto de la Patagonia septentrional.

Valcheta es una localidad con una importante densidad histórica, ya que ese espacio fue un eje central del control territorial indígena previo a las campañas militares de fines del siglo XIX. Asimismo, Valcheta era una verdadera encrucijada de caminos que conectaba históricas rastrilladas indígenas, las cuales seguían diferentes orientaciones hacia puntos como Maquinchao, Carmen de Patagones o el valle inferior del río Chubut (Ezcurra, 1898;

1 Una versión preliminar ha sido presentada en las XV Jornadas Interescuelas de Historia, el 17 de septiembre de 2015.

2 El Territorio Nacional de Río Negro fue creado como unidad administrativa en 1884 mediante la Ley $\mathrm{N}^{\circ} 1532$. Las campañas militares de conquista de la Patagonia septentrional se desarrollaron entre fines de la década de 1870 y mediados de 1880 , lo que implicó un proceso gradual de sometimiento de las poblaciones indígenas.

3 Se han identificado subregistros censales de árabes en otras regiones de la Argentina. Akmir atribuyó esa particularidad a que los sirio-libaneses temían las eventuales consecuencias negativas de los censos (2011, p. 44).
Deodat, 1958; Casamiquela, 1985; Lista, 1998). El pueblo se fundó oficialmente como colonia pastoril, dentro del Departamento 25 de Mayo, mediante un decreto que se promulgó el 19 de junio de 1889. Para 1912 ese Departamento contaba con 3.034 habitantes, de los cuales 192 residían en Valcheta (Ministerio del Interior [MI], 1914, p. 266). Los pobladores de la región eran, en su mayoría, crianceros ocupantes de campos fiscales de manera permanente, dispersa y sobre los bordes de la meseta del Somuncurá (Moldes, 1998, p. 125). Las inspecciones de tierras ratifican las conclusiones censales en relación con la gran dispersión de los pobladores en la zona de influencia de Valcheta, una característica que también se verificó en el caso de los sirio-libaneses (Fig. 1).

Las inspecciones de tierras son documentos fundamentales para reconstruir la inserción territorial en la región, ya que ofrecen un registro pormenorizado de las principales características de los pobladores y sus condiciones materiales. No obstante, son parcialmente representativas de la situación de los ocupantes árabes, teniendo en cuenta que identificaron menos inmigrantes de ese origen que otras fuentes o lo hicieron de manera tardía 3 . En las inspecciones de tierras de 1912 se relevaron solamente tres ocupantes sirio-libaneses en Valcheta y sus zonas de influencia, mientras que en el censo de población del mismo año se habían registrado 8 turcos 4 (MI, 1914, p. 272). Existe además el problema de la identificación de los pobladores árabes en períodos subsiguientes, porque no siempre se registraba la nacionalidad de los ocupantes y algunas veces se confundía el origen de los apellidos sin advertir las modificaciones arbitrarias que habían producido los funcionarios de migraciones ${ }^{5}$. Asimismo, los documentos reflejan solo parcialmente la presencia de

4 Recuérdese que durante las primeras décadas del siglo XX se asimiló a los sirio-libaneses con los turcos, producto de que Siria y Líbano estuvieron coyunturalmente bajo el dominio del Imperio Otomano, sumado a que en algunos casos los inmigrantes de origen árabe ingresaban al país con pasaportes del gobierno turco.

5 En distintos repositorios documentales se evidenció el problema de los nombres castellanizados, por ejemplo, se registraron inmigrantes árabes identificados con apellidos como González, Luna o Lencina. Es decir, que los nombres personales no son un indicio suficiente para determinar el origen nacional de estos inmigrantes. 


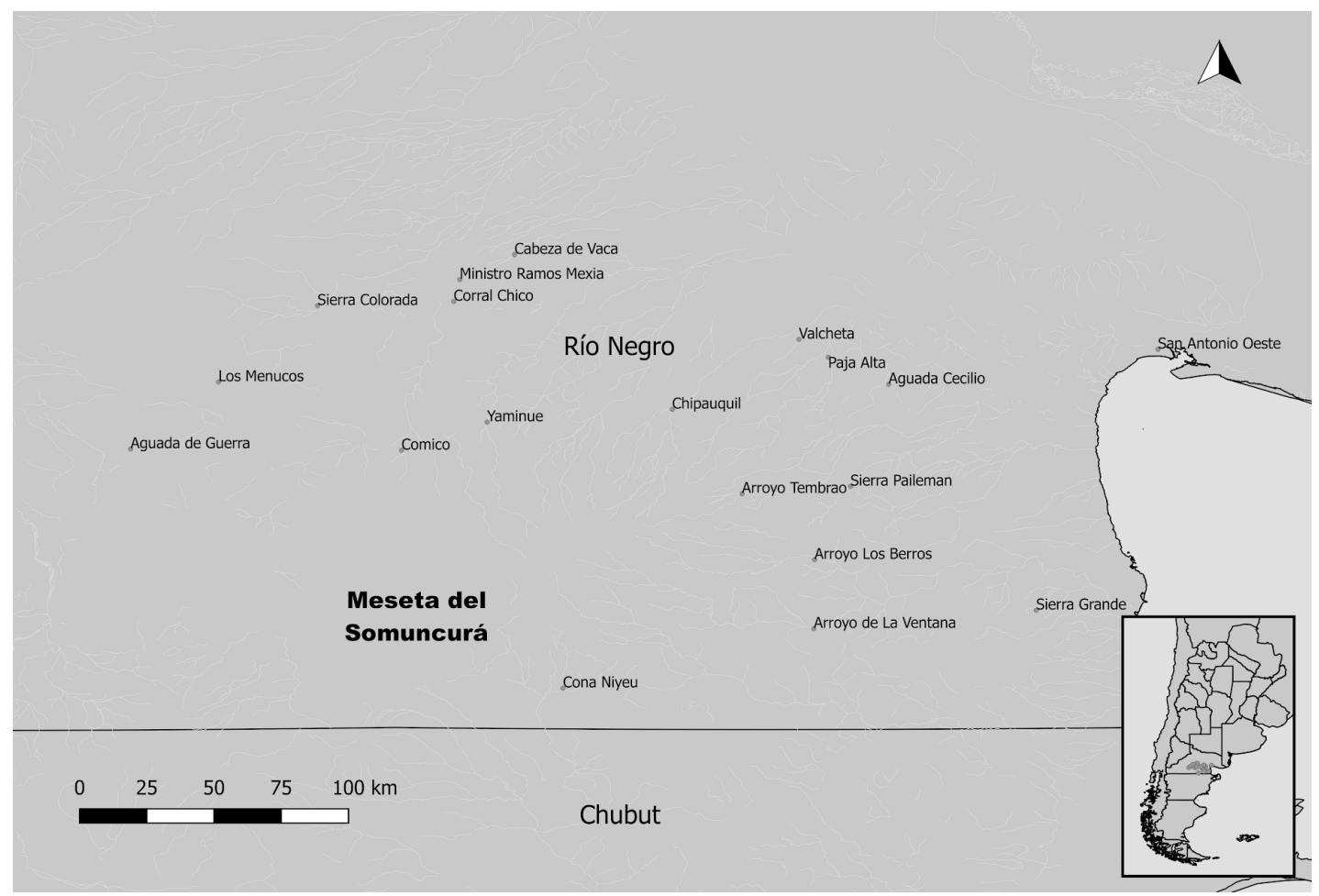

Fig. 1. Parajes con ocupaciones de sirio-libaneses en el sudeste de Río Negro durante el período de estudio, con énfasis en Valcheta y sus zonas de influencia.

árabes vendedores ambulantes, quienes constituyeron la primera avanzada inmigratoria y alentaron el arribo posterior de otros connacionales.

El sudeste de Río Negro fue un espacio bisagra en la inserción territorial de los siriolibaneses en la Patagonia, allí llegaron los comerciantes itinerantes desde Neuquén, General Roca o Bahía Blanca. Mientras algunos mercachifles se establecieron en Río Negro, otros siguieron camino al sur ${ }^{6}$. El principal motivo que impulsó a los pobladores árabes a la región fue la búsqueda de nuevos mercados porque otros nichos comerciales del país, como el litoral o el noroeste, eran altamente competitivos. El sudeste de Río Negro ofrecía mayores oportunidades de negocios y permitía vender mercaderías a un precio más elevado, especialmente cuanto más se alejaban de los puertos o de las estaciones del ferrocarril.

Existen importantes antecedentes de estudios sobre el acceso a la tierra en la Patagonia

6 Algunos de los árabes que operaron comercialmente en el sudeste de Río Negro se desplazaron posteriormente al noroeste de Chubut, radicándose incluso en la región luego de las campañas militares de expansión nacional, aunque no se ha trabajado directamente el problema de la inserción territorial de los inmigrantes árabes. Girbal-Blacha (1991) realizó una síntesis de la situación de la tierra pública en la región, profundizada luego por Bandieri (2005) y Blanco (2008). Barbería (1996) reconstruyó la distribución y concentración de la tierra en manos de grandes estancieros binacionales del sur de Argentina y Chile, para el Territorio Nacional de Santa Cruz. Por su parte, Bascopé (2008) partió del concepto de biopolítica para pensar las estrategias estancieras de sometimiento, erradicación y control de la circulación de poblaciones -vegetales, animales y humanas-, en un territorio subantártico como el de Tierra del Fuego en el que la presencia de los estados nacionales fue débil y tardía. En tanto que Blanco (2007) reconstruyó la ocupación territorial de Neuquén, describiendo las políticas estatales de distribución de tierra y analizando las estrategias

fronteriza con Chile y tendiendo redes de negocios de ambos lados de la cordillera de los Andes (Ivanoff Wellmann, 2013, p. 101). 
de los ocupantes para lograr la apropiación especulativa o productiva de la tierra. Por su parte, Ruffini (2001 y 2006) estudió la ocupación de la tierra en Río Negro, caracterizando las diferencias regionales a nivel ambiental y productivo, considerando la dinámica histórica de las distintas subregiones. También se registra una importante producción en relación con la ocupación del noroeste del Chubut (Finkelstein, 2001; Finkelstein \& Novella, 2005; Figueroa, 2010), destacándose la investigación de Sourrouille (2017), quien reconstruyó las relaciones de interacción y conflicto entre tres modelos de organización y uso de los recursos en esa región: la Colonia 16 de Octubre de galeses e inmigrantes, la reserva indígena Nahuelpan y la Argentine Southern Land Co., propiedad terrateniente de capitales británicos. Por otra parte, Delrio (2005 y 2008) y Pérez (2016) han discutido los mecanismos de expropiación de indígenas en Chubut y Río Negro, a partir del seguimiento de familias mapuches y mapuchetehuelches enfrentadas con las elites locales.

La discusión sobre la tierra pública en la Patagonia septentrional se inscribe en un debate mayor sobre la consolidación del Estado en la región. A comienzos del siglo XX el Estado argentino no había penetrado lo suficiente como para ejercer el gobierno efectivo sobre la propiedad en general y el territorio en particular, para ello resultó fundamental el control y reparto de tierras en zonas de frontera que permitió efectivizar su soberanía (Pro Ruiz, 2011, p. 20). Es decir, que la capacidad soberana no se dirimió solamente en el centro del poder estatal sino también en los bordes de esa autoridad. Se busca continuar el enfoque propuesto por Bohoslavsky y Soprano, estudiando al Estado desde una perspectiva descentrada, a través de las personas que efectivamente produjeron y actualizaron sus prácticas. Pensando al Estado como la manifestación de distintas fuerzas, muchas veces contradictorias y precarias, y no como un actor monolítico. Estos autores consideraron que estudiar los márgenes y las particularidades estatales brindará la posibilidad de apreciar las incapacidades, incoherencias y renuncias que también componen al Estado (Bohoslavsky \& Soprano, 2010, p. 27).

Sourrouille y Vezub (2014, p. 95) critican los enfoques historiográficos que tienden a reforzar falsos binarismos,
Uno de los tópicos que articula la literatura especializada en cuestiones de tierra pública es el rol de los inspectores de tierras. La mayoría de los trabajos específicos coincide en que los funcionarios de tierras fueron los mediadores fundamentales a la hora de determinar el éxito en la obtención de los derechos territoriales, y que fueron quienes promovieron una colonización planificada de los espacios periféricos (Almirón, 2012, p. 641). Los inspectores de tierras operaron como verdaderos productores identitarios, con capacidad para evaluar y clasificar a los pobladores, condicionando fuertemente las posibilidades de acceder a la tierra a partir de atributos como la raza y la nacionalidad (Baeza, 2009, p. 51; Blanco, 2016, p. 53). En algunos casos se ha señalado la visión dicotómica de los inspectores respecto de los pobladores de la región, a partir de clasificaciones que polarizaron la distinción entre inmigrantes europeos e indígenas (Baeza, 2007, p. 21). Como se verá, los inmigrantes sirio-libaneses escapaban a esa división binaria, introduciendo un factor de desestabilización de los sistemas clasificatorios. Profundizar la indagación sobre ese tipo de situaciones ambivalentes puede contribuir a complejizar los enfoques historiográficos ${ }^{7}$. Intentando avanzar en esa línea de análisis, a continuación se describe el contexto general del sudeste de Río Negro durante el período de estudio y se discuten los discursos de los funcionarios de tierras sobre los pobladores sirio-libaneses.

\section{El contexto regional y}

los discursos sobre los inmigrantes árabes

El sudeste de Río Negro fue un espacio de relocalización forzada de grupos indígenas luego de las campañas militares de expansión nacional, en ese contexto funcionó en Valcheta uno de los principales campos de reducción de prisioneros de la Patagonia (Vezub et al. 2016). De forma simultánea, según se desprende de la documentación oficial de tierras, tuvo lugar un proceso de inmigración de criollos y europeos a la zona, la mayoría de ellos provenientes de Carmen de Patagones. Estos nuevos ocupantes habrían realizado un rápido acaparamiento de tierras, especulando con la posible valorización

por ejemplo, aquellos que cristalizan la dualidad entre pioneros e indígenas. 
de las propiedades. Al poco tiempo, muchos de estos primeros inmigrantes abandonaron las ocupaciones sin haber consolidado proyectos agropecuarios exitosos, posiblemente afectados por los problemas que generaban las demoras en el otorgamiento de los títulos de propiedad.

$\mathrm{Si}$ bien los inspectores de tierras reconocieron las dificultades a las que se enfrentaban los pobladores, como el mal estado de las vías de comunicación y la escasez de agua, en última instancia responsabilizaron a los ocupantes por los problemas económicos y sociales. Los funcionarios insistían en la necesidad de mejorar los planteles ganaderos introduciendo razas más aptas, reclamaban la delimitación precisa de los lotes y la expansión de los campos irrigados, además de exigir que los pobladores cumpliesen con la construcción de las mejoras mínimas.

Los funcionarios de tierras criticaron las exiguas producciones agrícolas de los ocupantes, si bien reconocían que la opción ganadera era consecuente con las características ambientales de la región ${ }^{8}$. Los inspectores insistían en que se efectuaran perforaciones para obtener agua y que se construyeran canales de riego, además de instar a los pobladores para que lavaran la tierra para reducir su salinidad y levantaran cercos vivos que morigeraran los efectos erosivos del viento ${ }^{9}$. El

8 Los inspectores de tierras criticaban duramente las estrategias ganaderas de los pobladores locales, sin reconocer los saberes que sostenían sus prácticas: "Puede decirse que no existe una norma racional de explotación; todos o casi todos los ganaderos se limitan a dejar librados a su propia suerte a los ganados, dejando que todo se haga de acuerdo a las leyes de la naturaleza. Las únicas prácticas ganaderas que se efectúan se reducen a la esquila, la yerra y aparte de los carneros en cierta época del año. La explotación ganadera se hace a pleno campo y las únicas comodidades que se construyen para las haciendas se reducen a corrales de ramas con ramada para la época de la esquila y a bebederos anexos a los jaguales en los campos en que se han construido pozos" (AHPRN, Sección Tierras [ST], Inspecciones Generales de Tierras [IGT], Colonia Valcheta, 1920, f. 26).

9 El geólogo norteamericano Bailey Willis, que estudió las características ambientales de la región entre 1911 y 1912 , recomendó que el uso de los recursos hídricos fuese optimizado mediante la construcción de diques y canales de riego (1914, pp. 65-66).

10 Este tipo de situaciones fueron consignadas en las inspecciones que se realizaron en Valcheta durante 1920: "[...] los colonos que se encuentran aguas abajo se ven privados la mayoría de las veces de este precioso líquido por las necesidades que de él tienen los que se encuentran situados aguas arriba. Las principal inconveniente era la falta de agua, ya que las precipitaciones eran insuficientes y los costos de las excavaciones de pozos eran muy elevados. La disponibilidad de recursos hídricos fue la principal variable utilizada para determinar el precio de la tierra o los cánones de arrendamiento. El problema del agua se acentuaba por la ausencia de políticas regulatorias y ante la falta de control estatal, lo que generaba conflictos vecinales que muchas veces tuvieron resoluciones violentas ${ }^{10}$.

Los inspectores identificaban una serie de problemas comunes en toda la línea sur de Río Negro: los campos abiertos sin cercar, la sobrepoblación ganadera y la alta movilidad de los productores, quienes se desplazaban buscando mejores tierras o simplemente practicaban la trashumancia entre los campos altos de "veranada" y los bajos de "invernada". La crítica respecto de la fuerte movilidad de los pobladores estaba dirigida a los productores ganaderos y a los comerciantes itinerantes.

Los funcionarios de tierras concluían que las explotaciones eran rústicas, carentes de racionalidad económica y sin la tecnificación agropecuaria necesaria. Igualmente, consideraban lógico que los pobladores no mostrasen entusiasmo por realizar mejoras e invertir en tierras que no tenían la seguridad de poseer legalmente en un futuro ${ }^{11}$.

desavenencias que entre ellos mismos existen activadas en su mayoría por el uso del agua, degeneran siempre en incidentes sangrientos o en otros casos se traducen en una pérdida total de la cosecha pues algunos colonos creen hacerse justicia cerrando compuertas a objeto de no permitir el paso del agua al terreno de su vecino" (AHPRN, ST, IGT, Colonia Valcheta, 1920, f. 25)

11 El inspector de tierras que relevó Valcheta en 1920 fue contundente respecto de las consecuencias negativas que generaba la falta de garantías legales sobre la tierra: "Una de las primeras medidas que urge tome el Gobierno es la regularización de la situación en que se encuentran los colonos. La gente se encuentra cansada de esperar que le llegue el tan ansiado título de propiedad que les permitiría tener la seguridad de que son dueños del pedazo de tierra que ocupan y podrán en esta forma invertir mayores capitales en mejoras que hoy tienen paralizada por la inseguridad de la posesión" (AHPRN, ST, IGT, Colonia Valcheta, 1920, f. 38). El mismo inspector sumaba los inconvenientes que generaban los administradores de la Colonia Valcheta, quienes al parecer solían falsear datos y tergiversar informes para favorecer o perjudicar a los pobladores en función de sus simpatías personales. Esta situación habría motivado la emigración de los desfavorecidos y habría promovido la concentración de la tierra. 
Para la década de 1930 entre el $70 \%$ y el $75 \%$ de la tierra de la Patagonia seguía siendo fiscal, es decir, que esta no era propiedad de los pobladores que efectivamente la ocupaban y la trabajaban (Fisch, 1932, p. 12; Sarobe, 1943, p. 122). La incorporación de la Patagonia septentrional a la economía nacional implicó un fuerte proceso de concentración de la tierra. Pese a que durante el período se sancionaron normas jurídicas orientadas a fomentar la ocupación del territorio y el reparto de la tierra pública entre colonos, en la práctica se produjo una alta concentración de superficies dedicadas a la explotación extensiva de la ganadería ovina.

El primer instrumento legal que condicionó la política de tierras en la Patagonia fue la Ley N817 de "inmigración y colonización", conocida como "Ley Avellaneda", que fue sancionada en 1877 y estableció el marco legal fundamental, determinando la política inmigratoria y regulando el acceso a la tierra pública de los nuevos colonos. A través de esa ley se creó el Departamento General de Inmigración cuya principal función era, según el artículo 3: "Proteger la inmigración honorable y laboriosa y aconsejar medidas para contener la corriente de la que fuese viciosa o inútil". Entre otras tareas, dicho Departamento se debía encargar de orientar la inmigración hacia las tierras que el Poder Ejecutivo decidiese colonizar. La Ley Avellaneda también estableció la creación de la oficina de Tierras y Colonias, bajo la dependencia del Ministerio del Interior, cuyas principales funciones eran la exploración de tierras, el relevamiento de las condiciones de éstas y la recomendación del tipo de utilización. Esta ley propuso el reparto de tierras entre pequeños colonos y la venta mediante subastas públicas, excluyendo a los pobladores indígenas de esos beneficios y encomendando para ellos la creación de misiones.

El instrumento legal que favoreció el acaparamiento de tierras fue la Ley $\mathrm{N}^{\circ} 1265$ de 1882 sobre venta de tierras fiscales y división de los Territorios Nacionales, por la cual se habilitó la venta de hasta 40.000 hectáreas mediante remate público. Luego, con la sanción de la Ley de Hogar

12 Devoto señala que muchos inmigrantes tenían una vasta estructura comunitaria desde la cual defenderse y que: "[...] la adopción de la ciudadanía argentina implicaba en
Nº1501 en 1884, se intentó promover la creación de colonias agrícolas pastoriles, facilitando el acceso a la tierra de pobladores tipificados legalmente como intrusos (con la condición de que cumpliesen cinco años de residencia y hubiesen efectuado las mejoras mínimas exigidas). Esta ley estaba dirigida a ciudadanos argentinos y a extranjeros con cartas de ciudadanía o con intención de nacionalizarse, lo que dejaba por fuera a muchos inmigrantes indocumentados y a aquellos que no estaban dispuestos a nacionalizarse para no perder más beneficios de los que eventualmente podían obtener ${ }^{12}$.

El marco legal se modificó a partir de 1903 con la sanción de la Ley $\mathrm{N}^{\circ} 4167$ de régimen de tierras fiscales. En la práctica esta nueva ley no logró reducir las especulaciones ni el acaparamiento, a la vez que dificultó el acceso a la tierra de quienes podían probar residencia prolongada en un mismo lugar al dejar de considerar los antecedentes de la ocupación como un argumento con valor legal, lo que claramente perjudicaba a los pobladores indígenas. No obstante, esta última modificación, fue recurrente que los ocupantes se esforzaran por probar su mayor antigüedady los propios inspectores de tierras recogieron habitualmente testimonios de vecinos o policías como antecedentes del tiempo de residencia, es decir, que la antigüedad continuó siendo en la práctica un factor a considerar.

Hipólito Yrigoyen durante su primera presidencia buscó promover la colonización de pequeños propietarios y frenar el proceso de concentración de tierras en la Patagonia, aunque los instrumentos legales que intentó promulgar fueron obstaculizados en el Congreso por los grupos conservadores cercanos a los principales latifundistas de la región (Girbal-Blacha, 1991, p. 211). El gobierno nacional mediante un decreto sancionado el 18 de marzo de 1917 intervino la Dirección General de Tierras por encontrarse en situación de "total desorganización y abandono", y a partir de allí buscó detener la venta de tierras fiscales y declarar la caducidad de las concesiones previas. En ese sentido, el 4 de junio de 1917 se promulgó un decreto presidencial prohibiendo la introducción de mejoras en campos fiscales y

casi todos los casos la pérdida de los derechos sociales y la exclusión o expulsión de la comunidad étnica" (2009, p. 261). 
se ordenó el cese de los desalojos hasta tanto se informase el estado real de las ocupaciones. A partir de la aplicación de ese decreto se privilegió a los pobladores más antiguos, en clara contradicción con la ley de tierras de 1903 la cual negaba cualquier derecho por primera ocupación, porque desde entonces los gobernadores instruyeron a las fuerzas policiales para que expulsaran a los ocupantes que introdujesen mejoras.

Las inspecciones de tierras reflejan la falta de planificación y sistematicidad de las políticas estatales de tierras, las cuales eran fluctuantes y sufrian modificaciones parciales que intentaban resolver problemáticas coyunturales sin perspectivas de largo plazo. Los inspectores se mostraron especialmente críticos sobre los magros resultados de la legislación de tierras, señalando la distancia entre la normativa metropolitana y las prácticas locales. En los informes se verifica además que el marco jurídico muchas veces entró en contradicción con la aplicación práctica de la ley (Bandieri \& Blanco, 2009, p. 198).

Los funcionarios de tierras consideraron que el problema de la tierra pública era acuciante y que las leyes específicas habían fracasado en su intento por favorecer el arraigo de colonos capaces de realizar las mejoras que se consideraban necesarias. Los inspectores sugirieron el arrendamiento con derecho a compra, buscando estimular la concreción de las inversiones necesarias y ofreciendo a los pobladores garantías de que eventualmente obtendrían los derechos definitivos. Esa conclusión se apoyaba en que las alternativas de la venta pública y el arrendamiento simple habían fracasado. La venta de tierras a través de remates había generado el acaparamiento con fines especulativos y los arrendatarios sin derecho a compra no habían efectuado inversiones por miedo a perderlas. Los inspectores de tierras fueron los

13 Augusto Margueirat, el inspector de tierras que relevó el paraje El Salado en 1904, consignó: "Los pobladores de esta zona son en su totalidad paisanos (indios mansos) y chilenos naturalizados, gente toda sin hábitos de trabajo y sin mayores anhelos que los de poder vivir cuidando sus majaditas" (AHPRN, ST, IGT, Colonia Valcheta, 1904, f. 6). Mases (2014) se ocupó de analizar el discurso de los funcionarios estatales sobre los pobladores indígenas del sur de Río Negro.

14 Los boliches eran comercios rurales de escala intermedia, genéricamente identificados como almacenes de "ramos empleados estatales con mayor presencia en la región, quienes tuvieron la potestad de resolver los litigios territoriales y generalmente pudieron tomar decisiones con absoluta discrecionalidad.

Los inspectores de tierras no medían a todos los ocupantes con la misma vara sino que sus informes partían de sistemas clasificatorios previos que jerarquizaban a los pobladores según su origen nacional o étnico. Las críticas de los funcionarios fueron generalizadas hacia todos los ocupantes, aunque fueron más enfáticos frente a los crianceros clasificados como "indígenas" y "chilenos"13. Los empleados de tierras proponían como solución al problema de la composición social una política de sustitución de población a través de la promoción selectiva de inmigrantes europeos.

Los funcionarios de tierras tuvieron percepciones ambivalentes sobre los siriolibaneses, porque si bien valoraron positivamente el aporte migratorio de alguno de ellos, reprobaron las actividades comerciales que practicaban la mayoría de los árabes. Los inspectores fueron especialmente críticos de los boliches ${ }^{14}$, que eran el principal nicho laboral de los sirio-libaneses. La mirada ambigua sobre los árabes se registró tempranamente en las inspecciones de tierras en Valcheta:

Los pobladores existentes en las zonas I y II de Influencia y Pueblo y Colonia Valcheta pueden dividirse en dos grandes grupos: cristianos e indigenas. Entre los primeros están representadas distintas nacionalidades: argentinos, turcos, italianos, españoles, chilenos, etc. [...]

Los cristianos se encuentran en su mayoría en el pueblo y Colonia Valcheta $y$ se dedican unos a la agricultura, otros

generales". Estos establecimientos ofrecían para la venta diferentes productos como alimentos, herramientas, vestimenta o tabaco, en algunos casos brindaban también servicios de alojamiento, correo o expendio de combustible. Los boliches eran el principal espacio de sociabilidad del ámbito rural patagónico, en la mayoría de ellos se vendían bebidas alcohólicas al copeo. Estos comercios eran a su vez acopiadores de lana, plumas, cueros y cerdas, intercambios que propiciaban cadenas de financiamiento, en los casos en que los bolicheros adelantaban mercaderías a sus clientes. 
al comercio y muy pocos a la ganadería. En cambio, los indígenas constituyen la inmensa mayoría de los pobladores de los lotes pastoriles y se dedican pura y exclusivamente a la ganadería. Uno que otro turco se encuentra en los lotes pastoriles, dedicado al comercio (AHPRN, ST, IGT, zonas de influencia I y II de Valcheta, 1920 , fs. 15 y 16 , subrayado en el original).

En ese esquema los inmigrantes árabes parecían escapar a los dos grandes grupos de cristianos $e$ indígenas, si bien en principio eran subsumidos dentro del primer conjunto. En el marco de ese enfoque eminentemente dual, la conexión mercantil de los "turcos" los asociaba directamente a los ganaderos indígenas. Es decir, a los pobladores que fueron más duramente criticados por los inspectores de tierras. Aunque los sirio-libaneses no fueron despreciados de modo equivalente, tampoco se los consideró inmigrantes deseables. Esta posición intermedia y ambivalente introdujo un factor de crisis y desestabilización de las representaciones clasificatorias de los agentes estatales $^{15}$. Los sirio-libaneses no se ajustaban al proyecto estatal que promovía el arraigo de colonos agricultores, ya que ellos se dedicaban fundamentalmente al comercio ${ }^{16}$.

15 Desde la perspectiva de los inspectores de tierras los inmigrantes árabes eran problemáticos porque se especializaban en actividades comerciales: "En la Colonia y Pueblo Valcheta se encuentra la población que podríamos llamar civilizada, predominando entre ellos los Turcos que se dedican de preferencia al comercio que en esas zonas produce pingües beneficios. El italiano y el español, dedicados a la agricultura están en minoría y sus costumbres y modalidades por todos conocidas, hacen de estos elementos un factor de progreso cuya radicación en las zonas, interesa al gobierno fomentar" (AHPRN, ST, IGT, zonas de influencia I y II de Valcheta, 1920, f. 17).

16 En un texto clásico sobre la fundación de Valcheta se insiste en jerarquizar a los pobladores según su origen nacional o étnico, consolidando supuestas asimétricas entre europeos, sirio-libaneses e indígenas: "En el año 1925, quedó integrado el CONSEJO VECINAL que la ley garantizaba: la paciencia del árabe, la nobleza del español, la resignación del indígena y la vehemencia del italiano, fueron virtudes e impulso, que orientaron la conciencia de los pobladores, cuando el ahorro era una quimera en la era del centavo de cobre" (Ballor, 1968, p. 8). Los españoles e italianos eran claramente elogiados con valores activos y positivos, mientras que los árabes quedaban en un lugar
Las críticas de los inspectores de tierras a los inmigrantes árabes se conectaban con su marcado desprecio hacia los bolicheros en general, quienes eran estigmatizados como comerciantes parasitarios ${ }^{17}$. Este tipo de estereotipos sobre los bolicheros se verificó en las inspecciones de 1920, en ese caso en el tramo oeste de la línea sur de Río Negro:

Es así como se explica la profusión de esas casas [boliches] y el origen y rapidez con que se levantan abultados capitales a costa de la pasiva condición del indígena exprimido y absorbido por la voracidad ilimitada de ese elemento dañino que conviene eliminar por una racional selección al adjudicarse la tierra pública (AHPRN, ST, IGT, zonas de Quetrequile, Anecón Grande, Anecón Chico, Comallo, Coquelén, Laguna Blanca (sin mensurar), 1919-1920, f. 17).

Es interesante que el inspector explicitaba que el otorgamiento de adjudicaciones de tierras podía ser un filtro para eliminar a los comerciantes que, según su visión, se aprovechan de los pobladores indígenas. Los funcionarios asumían la tarea de detectar a los pobladores inconvenientes, producir informes desfavorables y eventualmente

ambiguo (adjudicándoles la dudosa virtud de la paciencia) y los indígenas eran definitivamente postergados en la resignación.

17 Los funcionarios de tierras fueron muy críticos de los comerciantes árabes en distintos espacios de la Patagonia septentrional, por ejemplo, el inspector que relevó la ocupación del bolichero Mario Breide en Cholila en el año 1920 consignó: "La comisión no puede sino informar que se trata de un comerciante, que como todos los de su nacionalidad en el territorio no aportan nada que pueda hacer en bien de la región en la que viven y trabajan. Examinando las cuentas de algunos de sus clientes, todos ellos pobladores del valle de Cholila y otras partes más o menos alejadas, se comprueban que la mayor parte de las anotaciones consignan entrega de bebidas alcohólicas y algunos géneros de extraordinario valor por lo elevado de los precios" (Instituto Autárquico de Colonización y Fomento Rural, IGT, sección JIII, 1920, f. 511). Es evidente la generalización del funcionario respecto de todos los comerciantes árabes de la región a partir de un caso puntual, enfatizando que los bolicheros vendían mercaderías a precios elevados y se especializaban en el expendio de bebidas alcohólicas. 
desaconsejar los permisos de ocupación. Se abría así un espacio de conflicto entre los inspectores y los comerciantes, en particular con los de origen árabe. A continuación, se presentan los resultados de las inspecciones realizadas en ocupaciones de pobladores sirio-libaneses, buscando precisar sus estrategias territoriales y describiendo las tensiones con los funcionarios estatales.

\section{Inspecciones en tierras ocupadas por árabes}

Las inspecciones de tierras de 1912 en la sección de Valcheta y sus zonas de influencia, que estuvieron a cargo de Eduardo Duffau, registraron a los tres primeros pobladores árabes. Uno de ellos fue Máximo Seleme, quien alegó una ocupación iniciada en 1901, aunque no había sido registrado en las inspecciones de 1904. El informe sobre el lote ocupado por Seleme se destaca por los detalles, el inspector subrayó en sus observaciones elementos que consideraba positivos, pese a que se trataba de una vivienda modesta. El funcionario

18 El inspector de tierras registró la existencia de las siguientes mejoras: "Población: Dos piezas y una cocina, hechas con paredes de adobe, techadas con pino de tea y hierro galvanizado todas ellas con sus correspondientes puertas y ventanas de tablas, pisos de tierra, de $4 \times 4$ metros cada una. A las que en conjunto se les puede asignar un valor aproximado de quinientos pesos, moneda nacional.

Alambrado: Hay un cuadro de terreno alambrado con estacones de ñandubay colocados a distintas distancias uno de otro, con cinco y seis hilos de alambre sin varillas, el que mide novecientos metros lineales y puede avaluarse en trescientos sesenta pesos, de igual moneda.

Plantaciones. Quinientas plantas, más ó menos, de álamos, mimbres y tamariscos.

Entre rastrojo y tierra preparada para la siembra existen aproximadamente nueve hectáreas.

Canal. Cuatrocientos ochenta metros de 1,20 metros de ancho, por 60 centímetros de profundidad de un costo aproximado de doscientos pesos moneda nacional.

Haciendas. En el día de la inspección pastaban en este lote dieciséis yeguas, un padrillo y once caballos de trabajo, marcados con la marca siguiente: cuyo boleto de marca exhibió y ha sido expedido a su nombre" (AHPRN, ST, IGT, Colonia Valcheta, 1912, s/f, subrayado en el original).

19 Buganem fue un vecino destacado de Valcheta, quien en 1939 fue elegido para pronunciar un discurso ante el gobernador de Río Negro en representación de la colectividad sirio-libanesa. En su alocución Buganem agradeció las gestiones realizadas y peticionó para que se construyesen obras de riego (Archivo del Museo Provincial María Inés Koop de Valcheta, Hemeroteca, fragmentos de prensa, s/f). valoró la construcción de cercamientos de alambre y la presencia de una incipiente producción agrícola. Asimismo, señaló la existencia de un canal de riego que optimizaba el uso del agua y permitía extender la superficie cultivada ${ }^{18}$.

Nader Buganem fue otro de los sirio-libaneses relevados ese año, quien posiblemente fue el poblador árabe mejor evaluado durante el período, lo que seguramente obedeció a su temprana inclinación por la agricultura y a la mayor solidez de sus edificaciones ${ }^{19}$. Sus mejoras se destacaban por el uso de ladrillos y por el blanqueamiento de las paredes con cal, algo poco frecuente en la región ${ }^{20}$. Buganem fue el único sirio-libanés clasificado como agricultor $^{21}$, aunque no se hicieron constar sus plantaciones hasta 1920. El inspector destacó en el informe de ese año, que: "[...] en una colonia con la mayoría de construcciones chatas y sin estética, la de Buganem se encontraba entre las únicas construcciones dignas de mención"22. Además, en la propiedad de Buganem funcionaba la oficina del Juzgado de Paz, un símbolo de prestigio reservado

20 En el informe se constataron las siguientes mejoras: "Hay en el edificadas en paredes de ladrillo asentados en barro, revocadas y blanqueadas por dentro, techadas con tirantes de pino tea y hierro galvanizado, dos habitaciones y una letrina, todas estas con sus correspondientes puertas y ventanas de tablas unas y vidrieras otras [...] Además una cocina hecha con tirantes de pino tea y hierro galvanizado (sin forrar) con una puerta y una ventana de tablas, piso de ladrillo asentados en barro. Al frente de las piezas un corredor de 1,50 metros de ancho por 8,50 metros de longitud, techado con hierro galvanizado sostenido por tirantes de pino tea, piso de ladrillos. Un pozo con brocal de tablas de 1,20 metros de diámetro, por 4,50 de profundidad. Esta casa está ocupada por el Juzgado de Paz de la localidad. Cercado en total en alambrado hecho en estacones de ñandubay, colocados a distancia de 12,50 metros uno de otro, siete hilos de alambre y cuatro varillas de hierro, entre estacón y estacón. Las mejoras que dejo detalladas existentes en este solar, le pertenecen a su concesionario Don Nader Buganem, por haberlo así comprobado en forma, esta administración" (AHPRN, ST, IGT, Colonia Valcheta, 1912, $\mathrm{s} / \mathrm{f})$.

21 Llama la atención que Buganem fuese identificado como agricultor considerando que él se reconoció como comerciante por lo menos hasta 1911, según consta en un expediente judicial de ese año en el que se lo acusó de defraudación comercial (AHPRN, Sección Justicia Letrada expediente $\mathrm{N}^{\circ} 8715,1911$ ).

22 AHPRN, ST, IGT, zonas de influencia I y II de Valcheta, 1920, f. 18. 
para los vecinos más influyentes. La donación de edificios públicos era una estrategia utilizada por comerciantes y hacendados para beneficiarse de eventuales reciprocidades por parte de los funcionarios estatales ${ }^{23}$.

La justicia de paz era un pilar fundamental del poder local que tenía bajo su jurisdicción todos los asuntos civiles hasta determinada suma y ejercía funciones de registro civil. Además, los juzgados de paz tenían:

[...] mucho control sobre el ámbito de la producción y el comercio. Eran los que extendian las guías de campaña que se utilizaban para transportar ganado $y$ frutos del país dentro y fuera del Territorio, debian registrar las marcas del ganado que definian su propiedad y también cobrar las patentes a los comercios de la localidad (Debattista \& Destéffaniz, 2000, p. 207).

En ese sentido, es posible que la relación especial de Buganem con el Juzgado de Paz lo haya posicionado de un modo privilegiado.

El último sirio-libanés mencionado en las inspecciones de tierras de 1912 fue Simón Nasif, en ese caso se observó que se había escriturado en su favor la manzana $\mathrm{N}^{\circ} 42$ de Valcheta, sin que consten detalles sobre las características de la ocupación. Unos años después las inspecciones de tierras de 1920 registraron más pobladores árabes, comprendiendo inmigrantes que se encontraban mayoritariamente dispersos en los parajes cercanos a Valcheta.

En ese contexto algunos de los sirio-libaneses realizaban ocupaciones simultáneas dentro de la misma región, incluso entre diferentes puntos de la línea sur de Río Negro, especialmente en los casos en que se trataba de comerciantes que establecían sucursales de sus boliches. Por ejemplo, Francisco Seleme que era vecino de Valcheta, ocupaba simultáneamente un solar en San Antonio Oeste. Otro caso fue el de José Zeitune, un comerciante

23 La donación de edificios públicos fue una estrategia de posicionamiento político y social utilizada por los inmigrantes sirio-libaneses en la Patagonia septentrional (Chávez, 2018).

24 Los sirio-libaneses tendieron a agruparse en espacios urbanos en distintas ciudades del país, el caso más radicado en Valcheta, que simultáneamente explotaba un boliche en el paraje Yaminué. Es decir, que los bienes patrimoniales y los intereses comerciales comenzaban a diversificarse y a desplegarse territorialmente.

En el sudeste de Río Negro los sirio-libaneses tendieron a aglutinarse dentro de las mismas manzanas o lotes ${ }^{24}$. La mayoría de los inmigrantes árabes ocupaba las tierras en calidad de "intrusos", inquilinos o como titulares de concesiones provisorias. Las ocupaciones más importantes, por su solidez y comodidades, eran las de Francisco Seleme y la de la firma comercial Chaher y Cía. (representada por Felipe Marón y Juan Miguel Chaher). Esta última firma tenía sede central en San Antonio Oeste y competía con los principales almacenes de la región, entre ellos la "S. A. Mercantil Podestá Lda." y la "S. A. Importadora y Exportadora de la Patagonia". Tanto Seleme como Chaher y Cía. arrendaban los lotes que ocupaban, el primero era inquilino de Felipe Guerrero, y los segundos de Pedro Contín. En estos casos la inserción comercial se produjo a partir del arrendamiento y sin efectuar la compra de los inmuebles.

En el año 1920 se inspeccionó nuevamente a Nader Buganem, en esa oportunidad el inspector recomendó regularizar su situación, y la de otros dos ocupantes linderos, ofreciéndoles la posibilidad de comprar la tierra. El funcionario dejó constancia de los antecedentes del lote, registrando que la primera concesionaria había fallecido sin haber cumplido con la ocupación personal que exigía la Ley del Hogar. La ocupante original del lote había vendido las mejoras a Felipe Guerrero, quien a su vez había transferido los derechos a Buganem. La estrategia de comprar mejoras como primer paso para luego reclamar la propiedad de los lotes, fue una maniobra difundida entre los inmigrantes árabes. No obstante, la adquisición de las mejoras no les garantizaba a los compradores derechos futuros sobre la tierra.

Una estrategia similar de acceso a la tierra fue la que utilizó el comerciante Emilio Rada, según

paradigmático fue el de Buenos Aires, donde se registró una fuerte concentración de inmigrantes árabes sobre la calle Reconquista (Bertoni, 1994, p. 73). En el caso de la Patagonia se destacan las concentraciones de sirio-libaneses que se produjeron en Ingeniero Jacobacci, Maquinchao y Gaiman. 
consta en las inspecciones del año 1929 en la sección II de Valcheta. Rada solicitó la compra y adjudicación de un lote cuyo concesionario original estaba ausente, contando con el aval de la policía local ${ }^{25}$. Este inmigrante al parecer aprovechó la disponibilidad de un lote que había sido identificado como deshabitado. El caso de Rada muestra una de las estrategias habituales que utilizaron los pobladores árabes para acceder a la tierra, la ocupación de un terreno identificado como ocioso y la introducción de mejoras, para luego de un tiempo reclamar la propiedad.

Otra de las estrategias empleadas por los inmigrantes sirio-libaneses para acceder a la tierra fue comenzar como arrendatarios. Muchos de los acuerdos de alquiler de los pobladores árabes se establecían con otros miembros de la misma comunidad de inmigrantes. En algunos casos la ocupación se concretaba a partir de permisos especiales de los concesionarios, sin que se registrasen acuerdos formales de arrendamiento. Llama la atención que no se registraron en la región casos de árabes en relación de medianería ${ }^{26}$, un tipo de acuerdo que fue una estrategia difundida de inserción en la producción ganadera, especialmente entre connacionales.

Los documentos de tierras muestran las críticas recurrentes de los inspectores hacia los inmigrantes árabes, si bien los ataques solían acentuarse en los informes generales y morigerarse en las inspecciones particulares. Los empleados de tierras mayormente recomendaban otorgar concesiones provisorias a los ocupantes siriolibaneses, aunque la concreción de los permisos quedaba supeditada a la introducción de las mejoras mínimas. Una de las pocas ocasiones en las que un

25 En el informe sobre el lote ocupado por Rada se observó: "El solar de que se trata fue dado en posesión provisoria a Don Luis Rojas en 2 de Noviembre de 1925 y aprobado por resolución 28 de abril de 1927 de la Dirección General. [...] Según el informe de la Policía de Valcheta que se acompaña, Don Luis Rojas se ha ausentado hace tiempo de esa localidad ignorándose el paradero actual del mismo [...] Luis Rojas, no ha cumplido con el Art. 809 del Reglamento de la Dirección General en el término fijado, correspondería en el presente caso en opinión del que suscribe, la aplicación del Art 823 del mismo Reglamento $y$, la formalización de una nueva concesión en favor del solicitante debiendo abonar el valor de la mejora que quedaría de propiedad fiscal. El interesado es una persona de responsabilidad pecuniaria que al mismo tiempo goza de inspector recomendó que se negase una concesión provisoria a un poblador sirio-libanés fue en el caso de Camilo Rada (hermano del mencionado Emilio). Camilo era propietario ausente de las mejoras del solar $\mathrm{C}$ de la manzana $\mathrm{N}^{\circ} 11$ de Valcheta, una vivienda que alquilaba a Segundo Graneros. El inspector determinó que por su precariedad: "Las mejoras detalladas no reúnen las condiciones de estabilidad, permanencia e higiene" 27 . No obstante, esas conclusiones fueron atípicas, pese a que en su mayoría las ocupaciones de inmigrantes árabes eran edificaciones precarias.

En muchos casos la Dirección General de Tierras denegó finalmente las concesiones provisorias porque los ocupantes árabes no se presentaron a realizar la solicitud correspondiente dentro de los tiempos estipulados, pese a que los informes de los inspectores habían sido favorables. Por ejemplo, durante el año 1928 en Los Menucos no se presentaron a regularizar su situación los pobladores Amado Manzur, Derecho Mussi y José Bichara $^{28}$. Tampoco se regularizó en ese momento la ocupación del matrimonio de Blanca Lencina y Emilio Ale (ambos sirio-libaneses), porque ella no pudo probar la unión conyugal ${ }^{29}$. En ese sentido, las mujeres eran consideradas legalmente incapaces y dependían de que sus cónyuges realizaran los trámites de tierras.

Resulta difícil proponer generalizaciones sobre las condiciones materiales de los siriolibaneses. No obstante, eran pocos los árabes que habitaban en espacios amplios con sólidas construcciones y relativas comodidades. La mayoría de estos inmigrantes ocupaba viviendas precarias que parecían utilizarse como moradas transitorias. Para completar el panorama general faltarían los

buen concepto en el vecindario" (AHPRN, ST, IGT, Colonia Valcheta, 1929, f. 151).

26 El inspector de tierras que relevó la Sección VII del sur de Río Negro sintetizó los acuerdos de medianería: "Para el cuidado de las haciendas los pobladores que poseen una cantidad apreciable de estas, forman lotes o majadas de 500 a 1000 ovejas, las que son entregadas a un puestero, quien percibe por lo general, el $50 \%$ de la esquila y del aumento, debiendo sufragar por su cuenta todos los gastos que demande el cuidado de la hacienda" (AHPRN, ST, IGT, Sección VII, 1920, f. 43).

27 AHPRN, ST, IGT, Colonia Valcheta, 1929, f. 153.

28 AHPRN, ST, IGT, Colonia Valcheta, 1929, f. 395.

29 AHPRN, ST, IGT, Colonia Valcheta, 1929, f. 402 
informes de los sirio-libaneses que no pudieron ser relevados porque estaban ausentes. Sus familiares $y$ vecinos solían aducir que estos pobladores se encontraban comerciando de manera ambulante, aunque es posible que algunos de ellos evitasen intencionalmente a los funcionarios ante la irregularidad de sus ocupaciones.

Los inspectores de tierras eran evidentemente quienes definían la situación de los ocupantes recomendando o desalentando el otorgamiento de las concesiones. Los funcionarios producían informes que supuestamente se basaban en estándares objetivos respecto de la calidad de las mejoras, aunque en realidad disponían de amplios márgenes para resolver en función de criterios arbitrarios.

Del relevamiento documental se desprende que la mayoría de los pobladores sirio-libaneses optó por el arrendamiento o la ocupación de tierras ociosas, sin que se hayan identificado litigios con los anteriores ocupantes, como sí ocurrió en otras regiones de la Patagonia septentrional. La mayoría de los ocupantes árabes solamente cumplió con las mejoras mínimas exigidas por la ley y tramitó los derechos de posesión provisoria. Los inspectores de tierras explicitaron que los comerciantes extranjeros, incluidos los árabes, no buscaban obtener permisos permanentes para establecerse como productores agrícolas, sino que les bastaba simplemente con "mantener su ubicación" 30 .

Un ejemplo elocuente de este tipo de estrategias territoriales se registró en Cona Niyeu durante 1920, donde había tres comercios importantes en un pequeño paraje con potencialidades agrícolas, dos de esos boliches pertenecían a inmigrantes sirio-libaneses (Felipe Zeitune y Alejandro González) ${ }^{31}$. Ambos eran prósperos comerciantes que habían requerido una baja inversión de capital, menos de 10.000 pesos cada uno. El diferencial de esos boliches era que estaban ubicados en una verdadera encrucijada de caminos, hacia distintos puntos: la meseta del Somuncurá, Arroyo Verde, el valle inferior del río Chubut, Sierra Colorada y San Antonio

30 AHPRN, ST, IGT, zonas de Quetrequile, Anecón Grande, Anecón Chico, Comallo, Coquelén, Laguna Blanca (sin mensurar), 1919-1920, f. 32.

31 AHPRN, ST, IGT, Sección VI, 1919-1920, fs. 204-209.
Oeste. Además, se trataba de un valle en el que se disponía de pasturas, agua y reparo de los vientos. Es decir, que en un lugar que los inspectores habían identificado como "totalmente apto para la agricultura", los ocupantes árabes solamente tenían intereses mercantiles. El anhelo de colonos agrícolas de los funcionarios estatales continuaba colisionando con las prácticas comerciales de los pobladores sirio-libaneses.

Es evidente que para los ocupantes árabes el acceso a la tierra fue el primer eslabón en la construcción de una territorialidad comercial, entendiendo por territorialidad "[...] el intento de un individuo o grupo de afectar, influir o controlar gente, elementos y sus relaciones, delimitando y ejerciendo un control sobre un área geográfica" (Sack, 1991, p. 194). Para los sirio-libaneses la tierra tuvo menos valor en tanto potencial territorio delimitado, que como un punto a partir del cual tender sus redes de negocios ${ }^{32}$. La precariedad de la mayoría de sus ocupaciones fue consecuente con la búsqueda de espacios de residencia temporal a partir de los cuales se especializaron en el comercio rural itinerante. Es decir, que la inserción en pequeñas localidades o parajes fue parte de una estrategia que buscaba generar plataformas desde las cuales desplegar redes comerciales.

\section{CONCLUSIONES}

Los resultados de este trabajo invitan a romper con miradas sesgadas que atribuyen a los inspectores de tierras visiones dicotómicas cerradas entre europeos e indígenas, ya que los inmigrantes sirio-libaneses eluden esa falsa dualidad. La percepción de los funcionarios de tierras sobre los ocupantes árabes fue evidentemente ambigua, si bien recomendaron que se les otorgasen permisos de ocupación provisoria, criticaron fuertemente sus actividades comerciales. La percepción ambivalente de los inspectores de tierras se refleja en que los sirio-libaneses fueron mejor valorados que los actores clasificados como "indígenas" y "chilenos", pero resultaron menos deseables que los inmigrantes europeos.

32 Para una reconstrucción de las redes sociales de los siriolibaneses en el sudeste de Río Negro, véase Chávez y Sourrouille (2016). 
Del análisis de los informes de tierras se desprende que los ocupantes árabes no tuvieron patrones homogéneos de residencia, aunque la mayoría de ellos ocupó tierras en carácter de intrusos aprovechando la vacancia de los lotes o insertándose como arrendatarios. Estos pobladores se establecieron mayormente en tierras urbanas pero orientados a los negocios comerciales en el ámbito rural y mostrando poco interés por realizar explotaciones agrícolas o ganaderas. Se verificó que los sirio-libaneses no estaban interesados en realizar las mejoras mínimas para acceder a la propiedad de la tierra, sino que les bastaba solamente con obtener los permisos para mantener su ubicación. La predilección de los pobladores árabes por las actividades mercantiles produjo una contradicción inevitable con los inspectores de tierras, quienes anhelaban colonos agricultores y criticaban los negocios que, desde su perspectiva, parasitaban a los crianceros indígenas.

La precariedad de las ocupaciones de los sirio-libaneses se puede comprender a partir de sus estrategias comerciales basadas en una baja inversión de capital y en una alta movilidad. La contradicción insalvable entre las prácticas de los pobladores árabes y los deseos de los funcionarios estatales se producía porque los primeros no tenían interés en establecerse definitivamente en un lote para especializarse en explotaciones agropecuarias. En cambio, los inmigrantes siriolibaneses se radicaban solo temporalmente en los parajes rurales, y desde allí intentaban construir una territorialidad comercial.

\section{BIBLIOGRAFÍA}

Akmir, A. (2011). Los árabes en Argentina. Rosario: Universidad Nacional de Rosario.

Almirón, A. (2012). Análisis sobre el papel de los inspectores de Tierras en el Territorio Nacional del Chaco. En H. Cansino, R. de la Mora, L. Medeiros de Menezes \& S. Moya (Eds.), Miradas desde la Historia Social y la Historia intelectual. América Latina en sus culturas: de los procesos independentistas a la globalización (pp. 641-669). Córdoba: Centro de Estudios Históricos Prof. Carlos S. A. Segreti; Facultad de Filosofía y Humanidades, Universidad Católica de Córdoba; Universidad Veracruzana, México. Instituto de Investigaciones Histórico-Sociales.
Baeza, B. (2007). Los inspectores de tierra como productores identitarios de la frontera chileno-argentina en Patagonia Central. VII Congreso de Histórica Patagónica argentino-chilena. Identidad e imagen. Historia, investigación e investigadores en Patagonia, Trevelin.

Baeza, B. (2009). Fronteras e identidades en Patagonia central (1885-2007). Rosario: Prohistoria ediciones.

Ballor, J. C. (1968). El campamento de necesidad. General Conesa: Centro documentario patagónico.

Bandieri, S. (2005). Del discurso poblador a la praxis latifundista: la distribución de la tierra pública en la Patagonia. Revista Mundo Agrario, 6(11), 1-18.

Bandieri, S., \& Blanco, G. (2009). Política de tierras en los Territorios Nacionales: entre la norma y la práctica. En G. Blanco y G. Banzato (Comps.), La cuestión de la tierra pública en Argentina. A 90 años de la obra de Miguel Ángel Cárcano (pp. 163-199). Rosario: Prohistoria ediciones.

Barbería, E. (1996). Los dueños de la tierra en la Patagonia Austral 1880-1920. Río Gallegos: Universidad Nacional de la Patagonia Austral.

Bascopé, J. (2008). Pasajeros del poder propietario. La Sociedad Explotadora de Tierra del Fuego y la biopolítica estanciera (1890-1920). Magallania, 36(2), 19-44.

Bertoni, L. A. (1994). De Turquía a Buenos Aires. Una colectividad nueva a fines del siglo XIX. Estudios Migratorios Latinoamericanos, 9(26), 67-94.

Blanco, G. (2007). La ocupación de la tierra pública en Neuquén: política distributiva, formas de tenencia y uso del suelo (1880-1920). Mundo Agrario, 7(14), 154183.

Blanco, G. (2008). Tierra y Ganado en la Patagonia: políticas públicas y conflictividad en las primeras décadas del siglo XX. Anuario del Centro de Estudios Históricos "Profesor Carlos S.A. Segreti", 8, 21-40.

Blanco, G. (2016). Los ocupantes de tierras en la Norpatagonia. Los Inspectores nacionales, el colono ideal y el poblador real al comenzar el siglo XX. Historia Regional, 29, 51-66.

Bohoslavsky, E., \& Soprano, G. (2010). Una evaluación y propuestas para el estudio del Estado en la Argentina. En E. Bohoslavsky \& G. Soprano (Eds.), Un Estado con rostro humano. Funcionarios e instituciones estatales en Argentina, de 1880 a la actualidad (pp. 9-55). Buenos Aires: Prometeo libros.

Casamiquela, R. (1985). Evocación del Valcheta Tehuelche. Revista Patagónica, 23, 14-16.

Chávez, M. (2018). De bolichero turco a ganadero árabe. La 
construcción territorial de un inmigrante libanés en el noroeste del Chubut (1907-1927). Páginas, Revista Digital de la Escuela de Historia de la Universidad Nacional de Rosario, 10(23), 84-100.

Chávez, M., \& Sourrouille, M. (2016). Redes sociales y territorialidad bolichera de sirios y libaneses en el sudeste de Río Negro, Argentina (1900-1950). Anuario de Historia Regional y de las Fronteras, 21(1), 159-181.

Debattista, S., \& Destéffaniz, C. (2000). El difícil arte de juzgar y ser justo. En M. Gentile, G. Rafart y E. Bohoslavsky (Comps.), Historias de sangre, locura y amor (Neuquén 1900-1950) (pp. 199-218). Neuquén: PubliFadecs.

Delrio, W. (2005). Memorias de expropiación. Sometimiento e incorporación indigena en la Patagonia. 1872 1943. Bernal: Universidad Nacional de Quilmes.

Delrio, W. (2008). Del cacique a la tribu: el caso de los hermanos Cual. Tefros, 6(1), 1-15.

Deodat, L. (1958). El golfo San Matías y las veredas indígenas rionegrinas. Runa, archivo para las ciencias del hombre, 9, 391-404.

Devoto, F. (2009). Historia de la inmigración en la Argentina. Buenos Aires: Sudamericana.

Ezcurra, P. (1898). Camino indio entre los ríos Negro y Chubut. La travesía de Valcheta. Boletín del Instituto Geográfico Argentino, 19, 134-138.

Figueroa, L. (2010). Las tierras destinadas a pastos comunes en Cholila: aportes para definir al sujeto poblador y pensar los cambios en el uso y tenencia de la tierra. Revista Hermeutic, 9, 1-21.

Finkelstein, D. (2001). Mecanismos de acceso a la tierra y narraciones de identidad en la colonia pastoril aborigen de Cushamen (provincia del Chubut). Cuadernos del Instituto Nacional de Antropología y Pensamiento Latinoamericano, 19, 231-247.

Finkelstein, D., \& Novella, M. (2005). Poblamiento del Noroeste del Chubut. Aportes para su historia. Esquel: Fundación Ameghino.

Fisch, R. (1932). Cuestiones patagónicas. Tierras fiscales y otros problemas. Buenos Aires: Kidd.

Girbal-Blacha, N. (1991). Política de tierras públicas en la Argentina (1916-1930). El caso de los territorios nacionales del Sur. Revista de historia del derecho, 19, 209-243.

Ivanoff Wellmann, D. (2013). Bolicheros y pobladores: una relación de frontera. Santiago de Chile: Consejo Nacional de la Cultura y las Artes.

Lista, R. (1998). Exploración al Río Negro y Chubut. En J. Carman (Comp.), Obras (pp. 351-369). Tomo 1.
Buenos Aires: Confluencia.

Mases, E. (2014). A veces Bárbaro, a veces civilizado, siempre vago y ladrón. En J. L. Lanata (Comp.), Prácticas genocidas y violencia estatal en perspectivas transdisciplinar (pp. 52-64). San Carlos de Bariloche: IIDyPCa-CONICET.

Ministerio del Interior. (1914). Censo de población de los Territorios Nacionales (1912). Buenos Aires: Guillermo Kraft.

Moldes, B. (1998). Plumas, pieles, tejidos y ganado. Contribución al conocimiento de la transición del sector social con economía doméstica en Somuncurá. En R. Masera (Comp.), La Meseta Patagónica del Somuncurá. Un horizonte en movimiento (pp. 75206). Viedma: Gobierno de la provincia del ChubutGobierno de la provincia de Río Negro.

Pérez, P. (2016). Archivos del silencio. Estado, indígenas y violencia en la Patagonia central, 1878-1941. Buenos Aires: Prometeo libros.

Pro Ruiz, J. (2011). Introducción. Mensuras, catastro y construcción estatal. En J. C. Garavaglia y P. Gautreau (Eds.), Mensurar la tierra, controlar el territorio. América Latina, siglos XVIII-XIX (pp. 13-25). Rosario: Prohistoria ediciones.

Ruffini, M. (2001). La cuestión de la tierra pública en Río Negro. Avances y perspectivas (Siglo XIX hasta la primera mitad del siglo XX). Anuario del Centro de Estudios Históricos "Profesor Carlos A. Segreti", 1, 95-111.

Ruffini, M. (2006). Estado y propiedad de la tierra en el Territorio Nacional de Río Negro: la cuestión de los ocupantes (1884-1892). En E. Cruz \& R. Paoloni (Comps.), Anuario del CEIC 3. La propiedad de la tierra. Pasado y presente. Estudios de arqueología, historia y antropología sobre la propiedad de la tierra en Argentina (pp. 147-167). Córdoba: Alción editora.

Sack, R. (1991). El significado de la territorialidad. En P. Pérez Herrero (Comp.), Región e Historia en México (17001850): Métodos de análisis regional (pp. 194-204). México: Universidad Autónoma Metropolitana.

Sarobe, J. M. (1943). La Patagonia y sus problemas. Estudio geográfico, económico, político y social de los Territorios Nacionales del Sur. Buenos Aires: Editorial Guillermo Kraft Ltda.

Sourrouille, M. (2017). Nahuelpan, Colonia 16 de Octubre y Argentine Southern Land Co.: la colonización del Territorio Nacional del Chubut (1885-1937) (Tesis doctoral). Universidad de Buenos Aires, Buenos Aires.

Sourrouille, M., \& Vezub, J. (2014). ¿Largos peregrinajes 
en el vacío? Indagaciones sobre desplazamientos de indígenas y colonos en la Patagonia central. En $\mathrm{H}$. Vessuri y G. Bocco (Coords.). Conocimiento, paisaje y territorio. Procesos de cambio individual y colectivo (pp. 93-115). Río Gallegos: Universidad Nacional de la Patagonia Austral, Centro de Investigaciones en Geografía Ambiental-UNAM, Centro Nacional Patagónico, Universidad Nacional de Río Negro.

Vezub, J., Sourrouille, M., \& Chávez, M. (2016). El campo de Valcheta. Indígenas, reducto y control social en la Patagonia norte (1830-1890). Jornadas un siglo de migraciones en la Argentina contemporánea (19142014), Buenos Aires.

Willis, B. (1914). El Norte de la Patagonia. Naturaleza y riquezas. Tomo I. Estudio de los elementos del tráfico del ferrocarril nacional de fomento desde Puerto San Antonio hasta el lago Nahuel Huapi y sus ramales dentro de la cordillera hasta su extensión internacional con término en Valdivia en Chile. Texto y mapas por la Comisión de Estudios Hidrológicos. New York: Scribner Press.

\section{Otras fuentes}

Archivo Histórico de la Provincia de Río Negro. Sección Tierras, 1904-1930 y Sección Justicia Letrada, 1911.

Archivo Histórico del Instituto Autárquico de Colonización y Fomento Rural de Chubut. Sección Tierras, 1920.

Archivo del Museo Provincial María Inés Koop de Valcheta. Hemeroteca. 